\title{
GRUPO DE AJUDA A ALCOOLISTAS: A EDUCAÇÃO EM SAÚDE NA ESTRATÉGIA SAÚDE DA FAMÍLIA
}

Marjorie Ester Dias Maciel$^{1}$, Sandra Cristina Pillon²

RESUMO: O presente artigo tem como objetivo relatar a experiência de educação em saúde de uma Estratégia Saúde da Família direcionada a pessoas com dependência alcoólica e seus familiares, mediante a estratégia de grupo de ajuda. Durante as reuniões do grupo, houve a troca de experiência entre os alcoolistas e seus familiares. Quinze pessoas frequentavam assiduamente as reuniões, das quais sete eram alcoolistas. Com a sua participação no grupo, verificouse a redução do consumo de álcool e abstinência alcoólica por algum período, bem como comportamento de busca pela saúde. Assim, a criação deste grupo demonstrou ser eficaz e coerente com a implantação do novo paradigma de assistência à saúde.

PALAVRAS-CHAVE: Alcoolismo; Redução do dano; Saúde da família.

\section{SUPPORT GROUP ON ALCOHOLISM: HEALTH EDUCATION IN THE FAMILY HEALTH STRATEGY}

\begin{abstract}
This paper aims at reporting the experience of health education in an Family Health Strategy, targeted to people with alcohol dependence and their families, through the strategy of support group. During group meetings there was exchange of experience among alcoholics and their families. Fifteen people attended assiduously the meetings, of which seven were alcoholics. Through their participation in the group, there was a reduction in alcohol consumption and alcohol abstinence for some period, as well as the health-seeking behavior. Thus the creation of this group proved to be effective and consistent with the implementation of the new paradigm of health care.
\end{abstract}

KEYWORDS: Alcoholism; Harm reduction; Family Health.

\section{GRUPO DE AYUDA A ALCOHÓLICOS: LA EDUCACIÓN EN SALUD EN LA ESTRATEGIA SALUD DE LA FAMILIA}

RESUMEN: El presente artículo tiene como objetivo relatar la experiencia de educación en salud de una Estrategia Salud de la Familia dirigida a personas con dependencia alcohólica y sus familiares, por medio de la estrategia de grupo de ayuda. Durante las reuniones del grupo, hubo cambios de experiencia entre los alcohólicos y sus familiares. Quince personas frecuentaban asiduamente las reuniones, de los cuales siete eran alcohólicos. Con la participación en grupo, se ha verificado la reducción del consumo de alcohol y abstinencia alcohólica por algún periodo, así como comportamiento de buscar por la salud. Así, la creación de este grupo resultó ser eficaz y coherente con la implantación del nuevo paradigma de asistencia a la salud.

PALABRAS CLAVE: Alcoholismo; Reducción del daño; Salud de la familia.

\footnotetext{
${ }^{1}$ Enfermeira. Mestranda do Programa de Enfermagem Psiquiátrica da Escola de Enfermagem de Ribeirão Preto-EERP da Universidade de São Paulo-USP. Membro do Grupo de Estudo sobre Prevenção do Uso Nocivo do Álcool e ou Drogas CNPq/USP. Docente do Curso de Enfermagem das Faculdades de Administração de Fátima do Sul-FAFS.

${ }^{2}$ Enfermeira. Professor Associado do Departamento de Enfermagem Psiquiátrica e Ciências Humanas da EERP-USP. Líder do Grupo de Estudo sobre Prevenção do Uso Nocivo do Álcool e/ou Drogas CNPq/USP.
}

Autor correspondente:

Marjorie Ester Dias Maciel

Faculdades de Administração de Fátima do Sul

Rua Tenente Antonio João, 800 - 79700-00 - Fátima do Sul-MS, Brasil

Recebido: $28 / 01 / 10$

E-mail: marjorieester@yahoo.com.br

Aprovado: 23/07/10

Cogitare Enferm. 2010 Jul/Set; 15(3):552-5 


\section{INTRODUÇÃO}

O alcoolismo no Brasil é um sério problema, de alçada pública, que implica em altos custos para o sistema de saúde ${ }^{(1)}$. Ele traz consequências à saúde individual por danos neurológicos, gastrintestinais, cardiovasculares e psiquiátricos, e à saúde pública por aumento nos índices do absenteísmo, de violência urbana, doméstica e intrafamiliar, e dos acidentes de trânsito, dentre outros ${ }^{(2)}$.

Assim, no âmbito da saúde pública, o Sistema Único de Saúde (SUS) deve tomar medidas para prevenir ou minimizar os transtornos ocasionados pela dependência alcoólica.

Nesse contexto, um importante pilar de consolidação do SUS, a Estratégia Saúde da Família (ESF), tem por escopo realizar a promoção da saúde, a educação em saúde e a prevenção de doenças de uma população geograficamente delimitada. Na ESF, a multiprofissional e interdisciplinar ${ }^{(3)}$ exerce um importante papel na prevenção da dependência alcoólica e de outros transtornos relacionados ao álcool. Isso ocorre porque, ao ter um vínculo com a comunidade da sua área de abrangência e ao buscar atingir seus objetivos, a ESF tem a possibilidade de identificar e intervir precocemente na dependência alcoólica, minimizando os seus danos na saúde da população. Outro fato que reforça a importância da ESF na prevenção do alcoolismo é a inclusão do mesmo pelo Ministério da Saúde na lista dos dez problemas de saúde prioritários para a ESF intervir ${ }^{(4)}$.

Dessa maneira, por conhecer a sua clientela e utilizar novas formas de assistência à saúde, mais resolutivas que a tradicional centrada na doença ${ }^{(5)}$, a ESF deve implementar estratégias que tenham alcance coletivo e que primem pela qualidade de vida, não excluindo os indivíduos dependentes do álcool.

Para tanto, a ESF tem como instrumento a educação em saúde, que faz parte das atribuições de todos os profissionais que compõe a equipe de Saúde da Família ${ }^{(3)}$. A educação em saúde pode ser definida como experiências de aprendizagem de modo a facilitar comportamento voluntário conducente à saúde ${ }^{(6)}$.

Nesse contexto, os grupos se configuram como uma importante ferramenta da educação em saúde, sistematizando a assistência e atingindo um número de pessoas maior ${ }^{(7)}$. Além disso, o trabalho com grupos possibilita uma relação mais horizontalizada entre os profissionais de saúde e a população, viabilizando o compartilhamento de saberes entre eles ${ }^{(8)}$.
Assim, buscando intervir junto à população dependente de álcool circunscrita a uma determinada ESF localizada na cidade de Vicentina, no interior do Mato Grosso do Sul, a equipe de Saúde da Família local resolveu criar um grupo de educação em saúde para alcoolistas e seus familiares. O objetivo é o de fornecer apoio aos interessados em reduzir o consumo de álcool ou os danos causados pelo seu uso crônico, ao mesmo tempo em que atende as suas necessidades psicossociais, resgata a autoestima do cliente alcoolista e auxilia os seus familiares para que compreendam o processo de dependência alcoólica. Neste processo, se busca modificar a visão do senso comum de relacionar o alcoolismo com fraqueza moral, bem como inserir os familiares como co-autores no processo de recuperação do dependente alcoólico.

Dessa forma, o presente artigo relata a experiência vivida no grupo de ajuda a alcoolistas pela equipe de Saúde da Família.

\section{METODOLOGIA}

Primeiramente, a ESF, composta por um enfermeiro, um médico, um auxiliar de enfermagem e seis agentes comunitários de saúde, buscou verificar a magnitude do problema da dependência alcoólica na comunidade do bairro Jardim Vista Alegre, que é a área de abrangência da equipe. Para isso, realizou um levantamento do número de alcoolistas, através do cadastro das famílias, levantado pela Ficha A, preenchida durante as visitas domiciliares dos Agentes Comunitários de Saúde. Estes são membros da equipe de Saúde da Família que funcionam como elo entre os demais profissionais da equipe de saúde e a população ${ }^{(3)}$. O levantamento foi feito no período de agosto de 2009.

Com este levantamento, constatou-se que na comunidade havia 42 pessoas que faziam uso crônico de álcool e que estes tinham a idade média de 32 anos, sendo apenas um do sexo feminino. De posse dessas informações, a equipe reuniu-se e começou a pensar em estratégias para enfrentar esse problema.

Assim, considerando que a abstinência total do álcool é o ideal almejado para o dependente alcoólico, mas que ao mesmo tempo ela é difícil de se alcançar, pensou-se em ter como meta a redução de danos. Esta parte do princípio de maximizar o alívio e bem-estar individual ou coletivo tendo em mente a impossibilidade de existência de uma sociedade totalmente livre de drogas ${ }^{(9)}$. 
Então, partindo-se do princípio de que a família deve participar do processo de reabilitação e recuperação do indivíduo por ser o seu meio social primário ${ }^{(10)}$, optou-se em criar um grupo de ajuda aos alcoolistas da comunidade da qual a família pudesse também fazer parte. Assim, o grupo seria mais um lugar de terapia, um espaço em que essa clientela pudesse ser motivada a reduzir danos e os seus familiares pudessem compreender melhor a dependência alcoólica sob os pilares da prática de educação em saúde dialógica. Essa prática se diferencia da educação em saúde tradicional por ser pautada no diálogo, na relação horizontal entre profissional-cliente e na valorização do saber do outro ${ }^{(11)}$. Ao contrário, a tradicional parte de relações verticais, e o diálogo ditatorial do profissional de saúde se apresenta como detentor do saber, colocando-se em posição superior à do usuário do serviço de saúde.

A estratégia seguinte foi buscar parceria com lideranças locais. Nesse caso, os parceiros foram a Igreja Católica e os membros da comunidade que já exerciam trabalhos voluntários e que eram lideranças comunitárias. Realizou-se uma reunião com os mesmos para esclarecer os objetivos da formação do grupo de apoio e detalhar como seria a forma de trabalho. $\mathrm{O}$ espaço onde aconteceriam as reuniões seria o salão paroquial cedido pela Igreja Católica.

A próxima etapa foi convidar a população alvo a compor o grupo, que eram os alcoolistas e seus familiares. O convite se deu através das visitas domiciliares de rotina dos Agentes Comunitários de Saúde, no mês de setembro de 2009, e nas visitas dos outros membros da equipe. $\mathrm{O}$ argumento para que $\mathrm{o}$ público-alvo aceitasse participar do grupo foi falar da importância em saber mais sobre a dependência alcoólica.

Assim, o convite foi bem acolhido pela comunidade, e mesmo aqueles que não garantiram estar presentes nas reuniões do grupo manifestaram-se positivamente frente à ideia da criação do grupo. Houve também o reforço dos voluntários da comunidade ligados a movimentos de grupos religiosos da Igreja Católica, que também fazem visitas mensais às famílias de baixa renda e com outros problemas sociais.

\section{RESULTADOS E DICUSSÃO}

Na primeira reunião, destinada a esclarecimentos sobre a proposta, compareceram aproximadamente 36 pessoas, entre alcoolistas e seus familiares.
Após a primeira reunião, o grupo começou a se formar de fato, permanecendo aqueles que realmente se interessaram pela proposta. Os encontros do grupo aconteciam uma vez por semana, tendo duração média de uma hora. As reuniões eram coordenadas pela enfermeira da equipe, com auxilio dos Agentes Comunitários de Saúde. Passaram a integrar o grupo assiduamente 15 pessoas, sendo sete alcoolistas e os demais familiares e pessoas que possuíam algum vínculo com estes.

Durante os encontros, havia troca de experiências entre os participantes. Desde a primeira reunião houve um contrato de sigilo entre os integrantes do grupo. Assim, cada experiência compartilhada deveria ficar somente entre os que estavam no grupo.

A troca de experiência no grupo é considerada uma grande aliada na recuperação do dependente ${ }^{(12)}$, funcionando como uma motivação na tentativa de abandono do comportamento como adicto.

Após alguns meses da existência do grupo, os alcoolistas participantes apresentaram mudanças de comportamento: a primeira foi a redução do consumo total de doses diárias de álcool, seguida do retardamento para o início da primeira dose do dia. Em dois clientes foi observado um período de abstinência, ainda que depois tenha havido uma recaída.

Os familiares passaram a ter uma concepção diferente do alcoolismo, percebendo que não se tratava de uma escolha, e sim de uma dependência, em que o beber torna-se compulsivo. Para os profissionais de saúde a experiência também serviu para aumentar laços de confiança e de aproximação com a comunidade. Todavia, o resultado mais importante foi a melhora da autoestima e da busca pelo cuidado com a saúde, por meio da procura do médico pelos alcoolistas para a realização de exames clínicos. Assim, ficou demonstrado que o grupo de ajuda estava cumprindo o seu papel de promover e educar para a saúde e de oportunizar uma melhora na qualidade de vida, apesar de não haver um grande número de participantes no grupo.

\section{CONSIDERAÇOES FINAIS}

Contrariamente à lógica capitalista, em que somente a produção em grande quantidade é um bom resultado, e ao modelo biomédico que preconiza somente a cura, os resultados obtidos constatam que o grupo de ajuda aos alcoolistas atingiu as metas que justificavam a sua criação. Este grupo também conse- 
guiu coadunar a sua proposta de execução de acordo com os preceitos da educação em saúde dialógica e da filosofia de trabalho da ESF.

Deve-se reconhecer, também, que o trabalho do profissional de saúde em realizar experiências desse tipo é duplamente complexo. Primeiramente, pelo estigma social que pesa sobre o alcoolista, do qual o profissional de saúde não está isento, pois há literatura atestando esse fato. E, em segundo lugar, devido à deficiência na formação universitária dos profissionais de saúde para a promoção da saúde e assistência integral, haja vista que muitos cursos de graduação da saúde ainda continuam formando profissionais sob a ótica curativista.

Assim, sugere-se que experiências como estas sejam apoiadas pelos gestores locais e que sejam amplamente divulgadas entre os profissionais de Saúde da Família, como um direcionamento para que outras iniciativas sejam implementadas para reduzir danos da dependência alcoólica.

Com relação aos usuários do serviço, estes serão os maiores beneficiados de trabalhos como este, podendo também haver a minimização de outros problemas ocasionados pelo alcoolismo para a saúde pública e sociedade.

\section{REFERÊNCIAS}

1. Lima JMB. Alcoologia: o álcool na perspectiva da saúde pública. Rio de Janeiro: Med BooK; 2008.

2. Barros MA, Pillon SC. Atitudes dos profissionais do programa de saúde da família diante do uso e abuso de drogas. Esc Anna Nery. 2007;11(4):655-62.

3. Batista SJ, Vasconcelos A, Martins C, Barros J, Soares J, Dutra B. Agente comunitário de saúde : percepções na estratégia da saúde da família. Cogitare Enferm. 2009;14(4):773 - 6.

4. Minto EC, Corradi-Webester CM, Gorayeb R, Furtado EF. Intervenções breves para o uso abusivo do álcool em atenção primária. Epidemiol Serv Saúde. 2007;16(3): 207-20.

5. Freitas FP, Pinto IC.Percepção da equipe de saúde da família sobre a utilização do sistema de informação da atenção básica - SIAB. Rev Latino-Am Enfermagem. 2005;13(4):547-54.

6. Candeias NMF. Conceitos de educação e de promoção em saúde: mudanças individuais e mudanças organizacionais. Rev Saúde Pública. 1997; 31(2):209-13.

7. Maffacciolli R. Os grupos na atenção básica de saúde de Porto Alegre: uso e modos de intervenção terapêutica [dissertação]. Porto Alegre (RS). Universidade Federal do Rio Grande do Sul; 2006.

8. Souza AC, Colomé ICS, Costa LED, Oliveira DLLC. A educação em saúde com grupos na comunidade: uma estratégia facilitadora da promoção da saúde. Rev Gaúcha Enferm. 2005; 26(2):147-53.

9. Soares JFS, Cezar-Vaz MR, Cardoso LS, Soares MCF, Costa VZ, Almeida MCV. O risco do uso de drogas no trabalho portuário. Esc Anna Nery. 2007;11(4):593-8.

10. Besen CB, Netto MS, Da Ros MA, Silva FW, Silva CG, Pires MF. A estratégia saúde da família como objeto de educação em saúde. Saúde Soc.2007;16(1):37-42.

11. Alves VS. Um modelo de educação em saúde para o Programa de Saúde da Família: pela integralidade e reorientação do modelo assistencial. Interface 2005; 9(16):39-52.

12. Jahn AC, Rossato VMD, Oliveira SS, Melo EP. Grupo de ajuda como suporte aos alcoolistas. Esc Anna Nery. 2007;11(4):645-9. 